\title{
François Rouget, Quelques éléments nouveaux sur les éditions anciennes de Du Bartas
}

\section{Filippo Fonio}

\section{(2) OpenEdition}

1 Journals

\section{Edizione digitale}

URL: http://journals.openedition.org/studifrancesi/35947

DOI: 10.4000/studifrancesi.35947

ISSN: 2421-5856

\section{Editore}

Rosenberg \& Sellier

\section{Edizione cartacea}

Data di pubblicazione: 1 juillet 2005

Paginazione: 149-150

ISSN: 0039-2944

\section{Notizia bibliografica digitale}

Filippo Fonio, «François Rouget, Quelques éléments nouveaux sur les éditions anciennes de Du Bartas»,

Studi Francesi [Online], 145 (XLIX | I) | 2005, online dal 30 novembre 2015, consultato il 19 avril 2021.

URL: http://journals.openedition.org/studifrancesi/35947 ; DOI: https://doi.org/10.4000/studifrancesi. 35947

Questo documento è stato generato automaticamente il 19 avril 2021.

\section{(c) (1)}

Studi Francesi è distribuita con Licenza Creative Commons Attribuzione - Non commerciale - Non opere derivate 4.0 Internazionale. 


\title{
François Rouget, Quelques éléments nouveaux sur les éditions anciennes de Du Bartas
}

\author{
Filippo Fonio
}

\section{NOTIZIA}

FRANÇOIS ROUGET, Quelques éléments nouveaux sur les éditions anciennes de Du Bartas, «Bibliothèque d'Humanisme et Renaissance», LXVI, 1 (2004), pp. 133-149.

1 Le opere di Du Bartas suscitano un grande entusiasmo al momento della pubblicazione, e vengono in breve tradotte fra l'altro in inglese, italiano, tedesco, spagnolo, latino. Lo studio in questione si concentra in particolare sulle edizioni cinquecentesche de $L a$ Sepmaine, La Seconde Sepmaine, Judith, La Victoire d'Yvry, riprendendo fra l'altro gli studi di Gilles Banderier sulle edizioni antiche delle opere di Du Bartas. Si tratta di: un esemplare dell'edizione partagée (Jacques Chouet e Jean Durant) della Sepmaine (Jacques Chouet, Genève, 1582), che presenta l'aggiunta di due componimenti latini in limine rispetto alla copia stampata da Durant e censita da Banderier; un esemplare dell'edizione Chouet, 1593 della Seconde Sepmaine, che comprende oltre al poema la Suite e l'Histoire de Judit, e presenta, a seguire i testi-soglia della Seconde Sepmaine, quelli relativi alla Sepmaine e l'indice di quest'ultima; un esemplare completo delle CEuvres poetiques di Du Bartas in due volumi (Genève, Pierre e Jacques Chouet, 1608); un esemplare di un'edizione pirata del Cantique sur la victoire d'Yvry (Nîmes, 1593). 